\title{
Research on University Computer Foundation Teaching in Blended Learning
}

\author{
Binbin Yu \\ ${ }^{1}$ Beihua University, College of Information Technology and Media, China \\ 22342690@qq.com
}

\begin{abstract}
Keywords: University computer foundation, Blended learning, Teaching design
\end{abstract}
\begin{abstract}
Teachers prefer the "arranged" classroom in the traditional teaching of university computer foundation that teacher leads classroom may make learners feel boring and cannot arouse learners' interest in depth study. Owing to the continuous progress of society and education, teaching ideas and teaching models are also constantly innovating and diversifying. Computer foundation for college students is the focus of the university basic curriculum and becomes more and more important. Specific principles of the blending learning was established and university computer foundation teaching in blended learning environment was designed in this article.
\end{abstract}

\section{Introduction}

With the development of the new generation of science and technology, such as Internet of things, large data, information fusion, the educational technology is also developing. It has led to the renewal of the educational philosophy of blending learning, the transformation of learning methods and so on. The development of educational information has been promoted by the emergence of mixed learning and mobile learning. Faced with fast knowledge and knowledge update speed, the traditional classroom is to ignore the dominant position of the learners and not conducive to stimulate the learning interesting of students. [1] University computer foundation plays an important part in university course. In university computer foundation courses teachers impress on lecturing-based teaching method, which is that teachers can effectively organize and monitor the teaching activities. But this simple teacher-led teaching may make learners feel that computer learning is boring and affect their interest in learning computer foundation. So it cannot effectively promote university computer teaching.

\section{Current Situation of University Computer Foundation}

In college education, university computer foundation which is a course combining theory with practice and has strong practicality and extensive practicability has always been one of the focuses of public course teaching. Students may be able to comprehend the true meaning from computer science and its relationship with other courses in the field, at the same time, the degree of mastering the computer foundation is also guaranteed by computer examinations at all levels. Teachers prefer the "arranged" classroom in the traditional teaching of university computer foundation that teacher leads classroom may make learners feel boring, cannot arouse learners' interest in depth study and cannot effectively promote university computer teaching. [2] Teachers require students to master the basic operations of graphic images and office applications so as to develop the students' ability of information literacy and solving professional knowledge.

Although the teaching content is more in this course, students need more computer practice after theoretical study. Current curriculum basically can satisfy the teacher to teach the theory knowledge, but the time is limited. So we can apply other teaching media, teaching methods, teaching environment to the classroom in order to play the learners' subjective initiative and enthusiasm. It may make learners' meaningful learning, develop learners' comprehensive and sustainable, and finally achieve the desired teaching effect. [3] 


\section{Blended Learning Theory and Application}

The Blended Learning Theory. There are different points of view on the connotation of blended learning between domestic and foreign scholars, according to the American Learning circuits blended learning is interpreted as a combination of traditional face-to-face learning and online learning and more development methods. [4] Chinese scholars Professor Kekang He believes that blended learning combines the advantages of electronic learning and traditional classroom learning methods. And at the same time it must fully embody the positive and novel creativity of the learners who are the main body of the learning process. [5] Online learning [6] breaks through the limitations of time and space in traditional classrooms, and the roles of teachers and students. In the online course online learning should be fully utilized by the students which can overcome the fear of public question. Online learning [7] creates more relaxed and innovative learning environment which stimulates students' learning interest and achieves optimized teaching results.

Blended Learning Application. According to the designed objectives of the university computer basic course, the cognitive structure of learners and the learning style, teachers design the teaching techniques suitable for learners. The university computer foundation in the blended learning environment can optimize and improve the teaching, promote learners meaningful learning, and effectively improve the teaching effect. Online learning platform for the majority of teachers and students to provide a new communication platform. According to the text data, video transmission, real time learning resources, learners study online or digital in a virtual classroom. In the course of teaching teachers should select and analyze the teaching media and combine a variety of teaching media organically so as to develop the function of teaching media. It can greatly promote the complete the teaching tasks, and eventually achieve the desired teaching effect.

\section{University Computer Foundation Course Teaching Analysis}

Analysis of Teaching Objectives. Knowledge and skills objectives: we usually ask the students to keep it firmly in hand the basics of computers which obtain Windows operating system for general knowledge and operation techniques, the use and operation of Microsoft Office software and so on; students are required to understand the basic principles of multimedia audio, video and so on. Process and method objectives [8]: teachers explore the educational model student-centered, teacher-led learning online and learning lines and combine. Attitudes and values objectives: the curriculum design should stimulate and guide learners to construct constructively and fully mobilize the learners' learning initiative and creativity. The analysis of teaching is shown in Fig. 1.

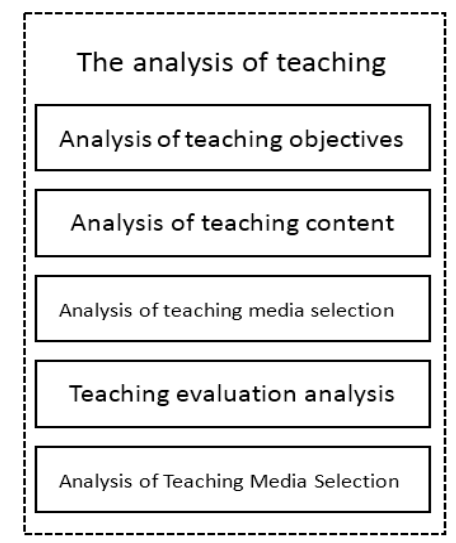

Figure 1. The analysis of teaching

Analysis of Teaching Content. The content is a required public course for non-computer majors. Computer system, which based on computer operating system, network technology, office information processing, computer networks, information retrieval and security, comprehensively enhance the level of computer culture foundation, optimize and improve the teaching, highlight the basic and practical 
knowledge of computer promote learners meaningful learning, and effectively improve the teaching effect.

Analysis of Teaching Media Selection. There are many factors that affect the choice of teaching media, such as the characteristics of the learner itself, the difficulty of the course, the teacher's own knowledge and skills, the nature of the discipline and so on. The choice of teaching media should not only consider the transfer efficiency, but take into account the cognitive effect. In order to create a better situation, stimulate learners learning and form the best combination of teaching effects, teachers choose to use multimedia computers, projectors and other teaching media.

Teaching Evaluation Analysis. Teaching evaluation [9], which can be divided into formative evaluation and summative evaluation. In conducting formative assessment, teachers should pay attention to motivating learners in their emotional attitudes so as to keep them interested in learning. Summative assessment is to evaluate the effectiveness of this semester after a period of teaching, such as the end of term. Teachers can also master the feedback information of students through interviews, questionnaires and other ways so as to understand the difficulties and practical needs of students in the process of learning.

Teaching Process Design. Pre-class design: the teaching process design includes pre-class design, the design in class and the design after class. Teaching evaluation is the value judgment of teaching process monitoring and teaching effect. Through teaching evaluation, summary and reflection, teaching design scheme analysis, design and implementation of the problems and shortcomings in the link, the teacher can modify and improve the teaching design plan appropriately as shown in Fig. 2.

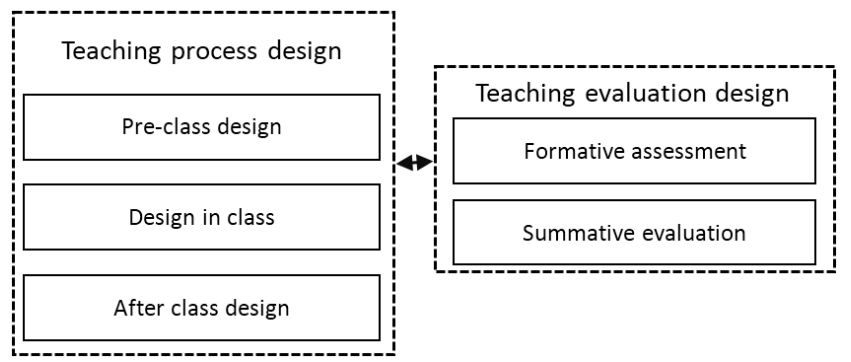

Figure 2. Curriculum design

The training of learners' awareness and ability of collaborative learning are payed more attention by online learning. Teachers use multimedia and other methods to promote and help learners make active construction of meaning in teaching. Through the network platform teachers upload micro video, text and other learning resources, and build interactive and personalized learning environment. Students can study online through the network platform without the restriction of time and space.

Design in class: in the network environment students can study and evaluate independently. They can practice online and get feedback to train students' good information literacy. The teacher has made good teaching design according to the knowledge. According to the feedback of students teachers can adjust the teaching progress appropriately and the degree of difficulty of the teaching content in time so as to optimize the teaching method and achieve better teaching effect. [10]In the process of the design in class teachers could select and analysis of teaching media, determine the use of teaching media, the organic combination of various teaching media assisted teaching in order to promote the teaching task successfully completed and finally get the ideal teaching effect.

After class design: teachers assign teaching tasks according to teaching objectives to promote students' cognitive level and learning ability of the subject. According to the students' learning feedback the teachers diagnose and remedy the students' after class learning content. In the after class session the teachers assign appropriate exercises to consolidate the knowledge so as to promote the students' interest in learning. Because the interest in learning can effectively promote learners' meaningful learning and help learners maintain and extract on the acquisition of meaning. Suitable after class design could optimize and improve university computer foundation course and promote meaningful learning and then improve teaching effects. 


\section{Summary}

With the continuous innovation and diversification of teaching methods, blended learning that promotes the teaching and has received extensive attention and recognition. Blended learning as an auxiliary teaching strategies can effectively promote the teaching of university computer foundation, which can inspire learners' interests, promote the consolidation and migration of the learners' cognitive structure and then achieve better teaching effect.

\section{Acknowledgements}

This work is supported by the Science and Technology Research Project of Jilin Province Education Department (Grant 2016057) and the Science and Technology Project of Jilin City (Grant 2015334001).

\section{References}

[1] Zhansheng Mu and Bojie Dong: Modern Educational Technology, Vol. 24 (2014) No.5, p.73-74. (In Chinese)

[2] Yu Zhao: e-Education Research, Vol. 253 (2014) No.5, p.92-93. (In Chinese)

[3] Puhua Li, Hongli Xue and Yutao Zhao, Journal of Higher Education Management, Vol. 10 (2016) No.6, p.89-90. (In Chinese)

[4] Guohua Wang, Shuyu Yu and Huifang Huang: Distance Education in China, (2015) No.2, p.29. (In Chinese)

[5] Kekang He: Curriculum, Teaching Material and Method, Vol. 36 (2016) No.2, p.7. (In Chinese)

[6] Wulin Ma and Xiaopeng Zhang: Technology Enhanced Foreign Language Education, Vol.139 (2011) No.5, p.50-51. (In Chinese)

[7] Yining Wang: The Theory and Practice of the Instructional Media (Higher Education Press, China 2007).

[8] Yusheng Sun, Yanan Cheng and Lijun Zhu: Journal of Distance Education, (2015) No.5, p.66-68. (In Chinese)

[9] Youru Xie and Kedong Li: Basic Research Methods on Educational Technology (Higher Education Press, China 2006).

[10] Xinglon Zhao: Modern Distance Education Research, Vol. 128 (2014) No.3, p.59. (In Chinese) 